\title{
Malignant melanoma of the rectum in an Iranian woman: a case report
}

\author{
Fatemeh Samiee Rad • Amir-Abdollah Zangivand
}

Received: 26 January 2012 / Accepted: 27 November 2012 / Published online: 14 December 2012

(C) Springer-Verlag London 2012

\section{Introduction}

Primary anorectal malignant melanoma is a rare disease attributing to only $1 \%$ of anorectal malignancies (Roviello et al. 2003; Takahashi et al. 2004). Approximately one malignant melanoma of the anorectal region is seen for every 250 and 8 adenocarcinoma and squamous cell carcinoma, respectively (Morson and Volkstadt 1963). Generally, anorectal malignant melanoma accounts for less than $2 \%$ of all melanomas (Hazzan et al. 2001). After the eyes and skin, anorectal region is the third most common site for it (Ballo et al. 2002; Fratesi et al. 2008). It typically tends to occur in women more often than men in the fifth or sixth decade, and the most common complaint is rectal bleeding, change in bowel habit, and pain (Roviello et al. 2003; Takahashi et al. 2004; Ballo et al. 2002). Unlike ocular and cutis forms, there is no relationship between cancer and exposure to ultraviolet light (Liptrot et al. 2009). Lesions are most commonly found at the anorectum, followed by the anal canal and anal verge (Righi and Dimosthenous 2008).

The tumor usually originated from or close to the pectinate line; therefore, it tends to grow toward the rectal ampulla (Mason and Helwig 1966). In the initially stage, it can simulate clinically thrombosed hemorrhoids or polyps (Tanaka et al. 2008; Sanchis Garcia et al. 2009). The overall prognosis is very poor with a median survival of 24 month and a 5-year survival of $10 \%$ (Solaz Moreno et al. 2005). Almost all patients die due to metastases (Maqbool et al.

F. S. Rad · A.-A. Zangivand

Qazvin University of Medical Sciences, Qazvin, Iran

A.-A. Zangivand $(\bowtie)$

Clinical Research Develop Unit, Bu Ali-Sina University Hospital, Qazvin, Iran

e-mail: zangivand@gmail.com
2004). We have outlined current diagnostic options of malignant melanoma of the rectum and review the literature.

\section{Case presentation}

The patient was a woman in his mid-60s who noticed in November 2010 with a 7-month history of changed defecation pattern, rectal bleeding, and pain associated with weight loss. There was no significant pathology in her past history or colon and/or rectal carcinoma in her family history. On physical examination, a $2.5-\mathrm{cm}$ polypoid mass was palpated in the anal canal with $3.5 \mathrm{~cm}$ distance from the anal verge. On rigid sigmoidoscopy studies, there was a polypoid pigmented mass at the anorectal angle. Biopsy demonstrated malignant cells with pleomorphic nuclei and abundant melanin in the cytoplasm. Computed tomography of the chest and abdomenopelvis and magnetic resonance imaging of the pelvis revealed well-preserved anorectal fat planes and no evidence of local invasion or distant metastasis. Dermatological and ophthalmological studies were not found evidence of a primary cutaneous or an ocular tumor. Immediately after her diagnosis, the patient underwent an abdominoperineal resection (APR). Macroscopic examination of APR specimen on the luminal aspect had shown a dark polypoid mass, $2.5 \mathrm{~cm}$ in diameter. Distance from proximal surgical margin and pectinate line was 16.3 and $1 \mathrm{~cm}$, respectively. The other part of mucosa was unremarkable. Regional lymph node was not found. She was in an uneventful postoperative period. Histopathologic examination of the resected specimen revealed malignant neoplasm in less cohesive growth pattern (Fig. 1). Individual markedly pleomorphic epithelioid tumoral cells characterized by high nucleus to cytoplasm (N/C) ratio, vesicular nuclei, occasionally multinucleated, prominent eosinophilic nucleoli, and abundant eosinophilic cytoplasm with distinct cell borders 
(Fig. 2). Melanin pigmentation and mitotic activities are noted (Fig. 3). Tumor invaded from the superficial epithelium into the submucosa. Junctional activity is present. Immunohistochemical studies for S-100 and HMB-45 were positive. The patient was currently followed up by the oncologist. She was considered for neoadjuvant therapy following repeat imaging. The patient was followed up for 6 months, and there were no further complications or any side effects.

\section{Discussion}

Primary malignant melanoma of the anorectal region is a rare and very aggressive rectal malignancy. It typically affects women in the fifth or sixth decade and often presents with rectal bleeding, tenesmus, or a change in bowel habit (Roviello et al. 2003; Takahashi et al. 2004; Solaz Moreno et al. 2005; Maqbool et al. 2004; Schaik et al. 2008). Malignant melanoma arises from melanocytes that have

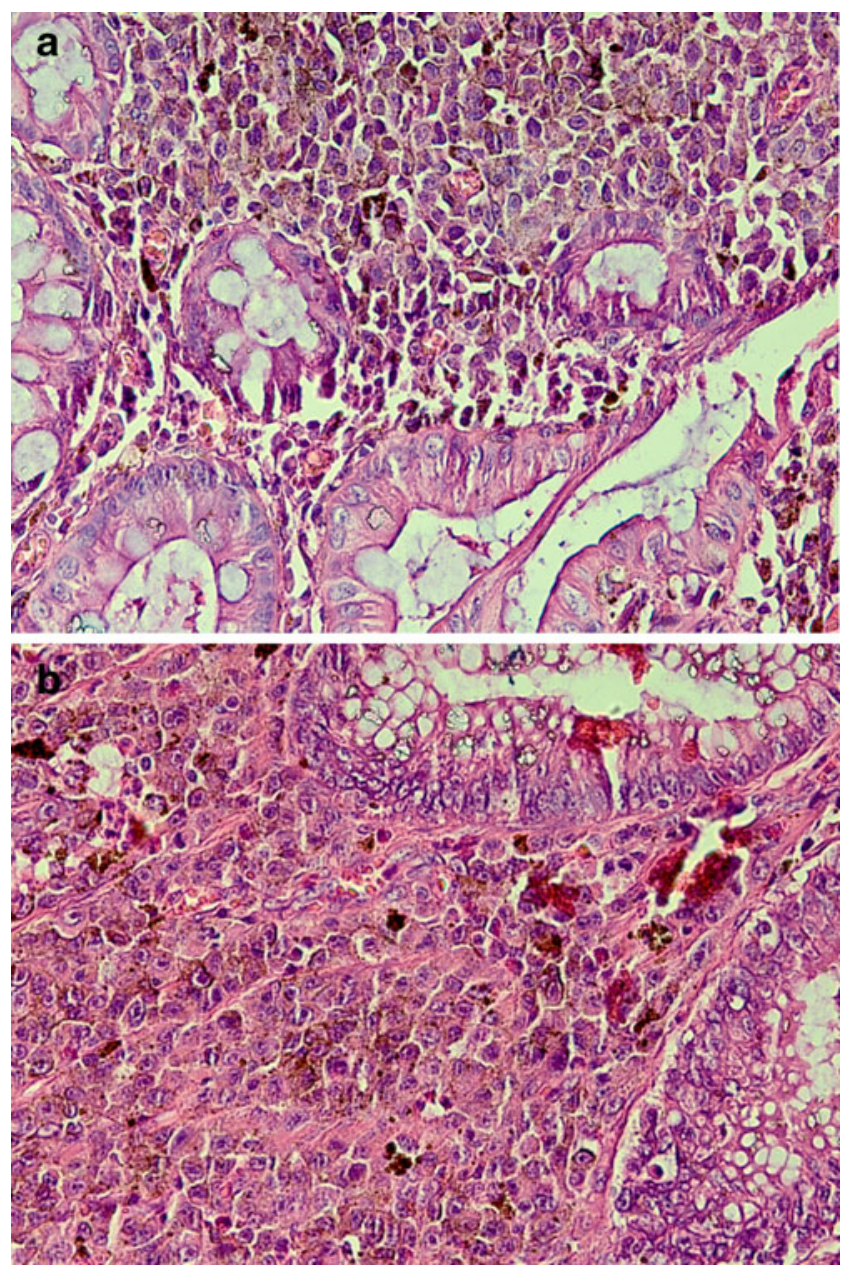

Fig. 1 a, b Malignant tumoral cells in rectal lamina propria that surrounded colonic glands [hematoxylin and eosin (HE), ×200]

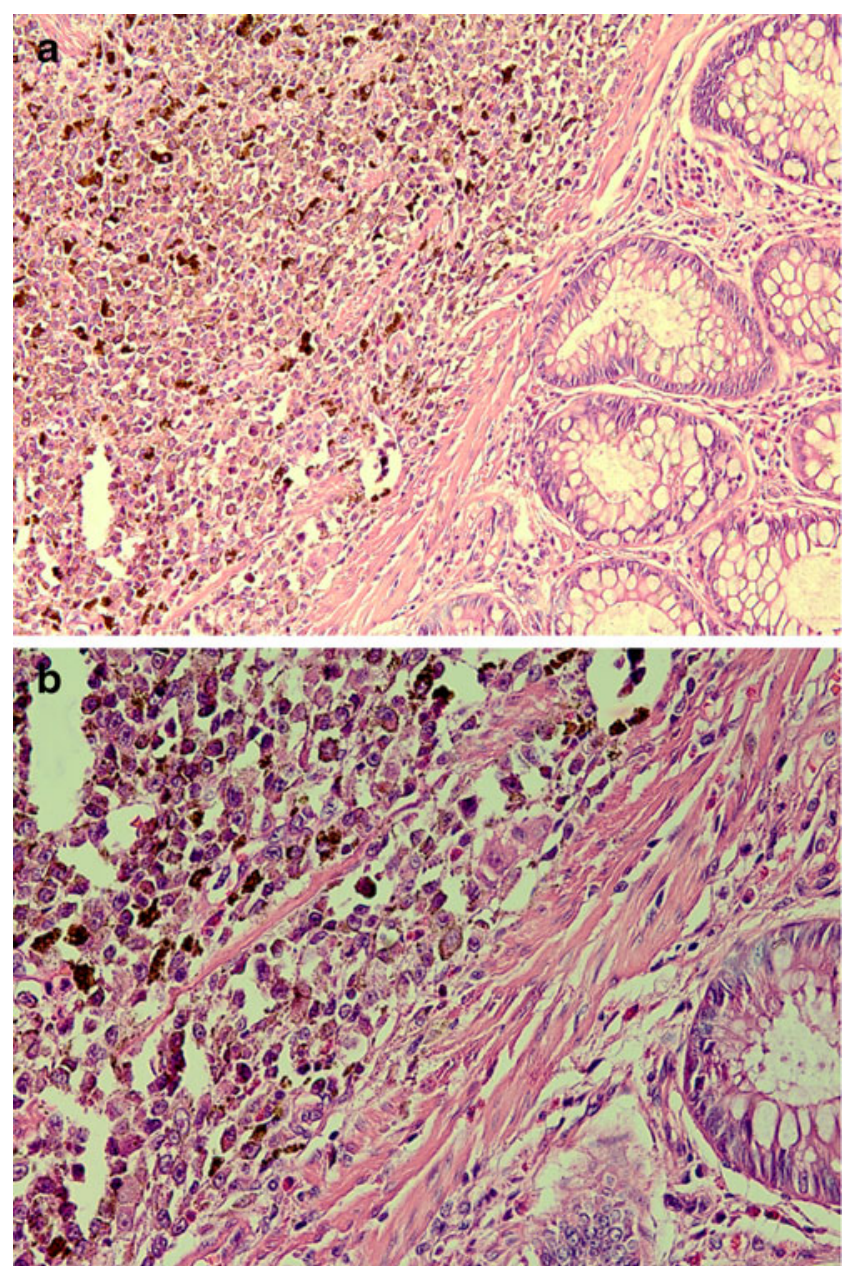

Fig. 2 a, b Malignant tumoral cells in rectal submucosa. a $(\mathrm{HE}, \times 200)$, b $(\mathrm{HE}, \times 400)$

migrated either from the neural crest or from mucocutaneous junctions and heterotopic, differentiated primitive stem cell (Nicholson et al. 1993). There are clinicopathologic

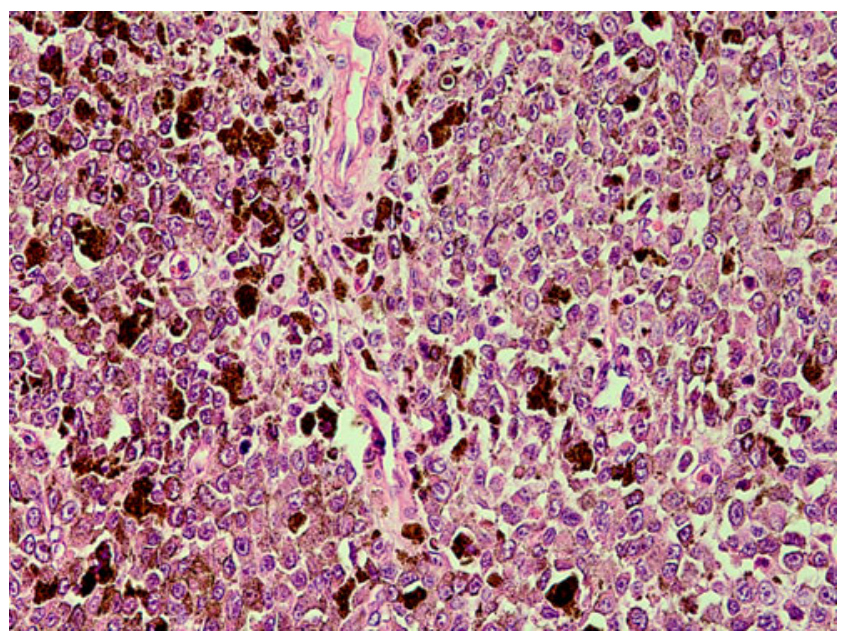

Fig. 3 Sheet of pleomorphic malignant melanocytes associated with melanin production $(\mathrm{HE}, \times 400)$ 
criteria to consider a melanoma primary in the gastrointestinal tract. Such criteria constitute the presence of atypical melanocytes between the base of the crypts and basement membrane, no evidence of elsewhere melanoma or no history of metastatic melanoma (Dong et al. 1999; Manouras et al. 2007).

Differential diagnosis of the anorectum tumoral mass varied from benign lesions, including hemorrhoids, hemangioma, polyps, and benign mesenchymal tumors, to malignant neoplasms that constitute adenocarcinoma, squamous cell carcinoma, malignant lymphoma, leiomyosarcoma, gastrointestinal stromal tumors, other malignant mesenchymal tumors, and metastasis (Rosai 2004).

Lesions are most commonly found at the anorectum, followed by the anal canal and anal verge. About $60 \%$ of patients at the initial diagnosis have already local or distant metastases (Takahashi et al. 2004).

Therefore, after confirmation of a malignant melanoma, subsequently dissemination studies, including chest X-ray and CT-scan of the chest/abdomen/pelvis, are performed. In a report published by van Schaik et al. (2008) in a 41-yearold man with rectal mass, the initial histopathologic diagnosis was as a leiomyosarcoma based on morphologic criteria, ultimately interpreted as a malignant melanoma according to immunohistochemistry studies including S100 protein. In a case described by Wang et al. (2007) in a 53-year-old woman with rectal mass, morphologic findings revealed a proliferation of small-sized malignant tumoral cells. These criteria probably were in favor of smallcell carcinoma or a lymphoma. With the application of immunohistochemistry, including S100 protein, HMB45, and the ultrastructural studies, it was reinterpreted as malignant melanoma (Wang et al. 2007).

van Schaik et al. (2008) believed that the first choice, among surgical therapies, seems to be local excision with adjuvant radiotherapy, and abdominoperineal resection should be performed in a large mass with obstruction. APR has some effect in decreasing symptoms caused by local and regional disease but has little impact on prognosis and patient outcome (Korenkov et al. 2008). Brady et al. (1995) and Wanebo et al. (1981) studies claim that an APR is the choice therapy. This fact is based on the hypothesis that the disease invades proximally through the submucosa into the mesenteric lymph nodes. A number of studies have shown a statistically significant improvement in localregional control when patients are managed with APR compared with local excision alone (without radiotherapy) (74 versus $34 \%$ ) (Hazzan et al. 2001).

The poor prognosis is related to several factors, and many of which are clearly interrelated: tumor size, depth of invasion, the advanced quality of the disease in the initial diagnosis, superficial ulceration, the good vascularity of the rectal mucosa, heightened risk of matogenous spreading, and the high aggressive biologic behavior of the tumors (Pantolone et al. 2000). In the more cases in the initial diagnosis, the tumor revealed regional and distant metastasis because MM has high metastatic potential (Antoniuk et al. 1993).

Cusati et al. (2011) reported two cases with rectal mass and clinical impression of primary rectal carcinoma with local lymph node metastases. In addition to the usual diagnostic challenges posed by primary melanoma anorectal, interpretation in these cases was made more difficult because of the small size of endoscopic biopsy and marked regressive changes, including cytolysis and chromatin smudging, which failed the accuracy of immunohistochemical studies. However, growth pattern of vital cells was solid nests or pseudoacini, similar to the commonly structures in conventional colonic adenocarcinoma. These phenotype (pseudoacini, glandular arrangement, and perinuclear vacuolation, and signet ring) was exceptionally rare but definitely described and published (Cusati et al. 2011). The tumor had high turnover, and finding of necrotic areas was a common phenomenon. Therefore, sometime morphologic studies of viable and intact tumoral cells were difficult. Also, accurate immunohistochemical evaluation was impossible (Cusati et al. 2011; Longacre et al. 1996). However, we did not find this phenomenon in examined sections.

Our case in APR specimen, atypical melanocytes (pleomorphic cells with high N/C ratio, vesicular nuclei, prominent nucleoli, and eosinophilic cytoplasm) in the superficial lamina propria, between the base of the crypts and basement membrane, are present and scattered within the normal mucosal cells. These findings confirmed by IHC studies. And also Cusati et al. (2011) and Werdin et al. (1988) studies documented this phenotype that compared with cutaneous junctional activity, which may be denoted by the "de novo" occurrence of colonic primary malignant melanoma.

\section{Conclusion}

Most primary care physicians and many pathologists and oncologists go through their entire professional careers without seeing an anorectal malignant melanoma. This is important to patients because misdiagnosis can delay the start of an appropriate treatment. The physicians at major cancer referral treatment centers, especially those with colonorectal teams, are much more likely to be familiar with malignant melanoma and its clinical awareness. Due to the little case report, the optimal management of anorectal malignant melanoma is still undecided; however, the tumor is aggressive malignancy; therefore, immediately and precise diagnosis is necessary. 


\section{References}

Antoniuk PM, Tjandra JJ, Webb BW, Petras RE, Milsom JW, Fazio VW (1993) Anorectal malignant melanoma has a poor prognosis. Int J Colorectal Dis 8:81-86

Ballo MT, Gershenwald JE, Zagars GK, Lee JE, Mansfield PF, Strom EA, Bedikian AY, Kim KB, Papadopoulos NE, Prieto VG, Ross MI (2002) Sphincter-sparing local excision and adjuvant radiation for anal-rectal melanoma. J Clin Oncol $20: 4555-4558$

Brady MS, Kavolius JP, Quan SH (1995) Anorectal melanoma. A 64year experience at Memorial Sloan-Kettering Cancer Center. Dis Colon Rectum 38:146-151

Cusati P, Sulfaro S, Salviato T, Falconieri G (2011) Epithelioid melanoma of the rectum: reappraisal of a deceptive microscopic simulator. Ann Diagn Pathol 15:52-57

Dong XD, DeMatos P, Prieto VG et al (1999) Melanoma of the gallbladder: a review of cases seen at Duke University Medical Center. Cancer 85:32-39

Fratesi L, Alhusayen R, Walker J (2008) Case report of primary rectal melanoma and review of the etiology of melanoma. J Cutan Med Surg 12(3):117-120

Hazzan D, Reissman P, Halak M, Resnick MB, Lotem M, Shiloni E (2001) Primary rectal malignant melanoma: report of two cases. Tech Coloproctol 5:51-54

Korenkov M, Gnner U, Dünschede F, Junginger T (2008) Rectal melanoma: the value of modern treatment [in German]. Zentralbl Chir 133:564-567

Liptrot S, Semeraro D, Ferguson A, Hurst N (2009) Malignant melanoma of the rectum: a case report. J Med Case Rep 3:9318

Longacre TA, Egbert BM, Rouse RV (1996) Desmoplastic and spindle-cell malignant melanoma. An immunohistochemical study. Am J Surg Pathol 20:1489-1500

Manouras A, Genetzakis M, Lagoudianakis E et al (2007) Malignant gastrointestinal melanomas of unknown origin: should it be considered primary. World J Gastroenterol 13:4027-4029

Maqbool A, Lintner R, Bokhari A, Habib T, Rahman I, Rao BK (2004) Anorectal melanoma-3 case reports and a review of the literature. Cutis 73:409-413

Mason JK, Helwig EB (1966) Ano-rectal melanoma. Cancer 19:39-50
Morson BC, Volkstadt H (1963) Malignant melanoma of anal canal. J Clin Pathol 16:126-132

Nicholson AG, Cox PM, Marks CG, Cook MG (1993) Primary malignant melanoma of the rectum. Histopathology 22:261264

Pantolone D, Taruffi F, Paolucci R et al (2000) Malignant melanoma of the rectum. Eur J Surg 166:583-584

Righi A, Dimosthenous K (2008) Primary malignant melanoma of the rectum arising against a background of rectal melanosis. Int $\mathbf{J}$ Surg Pathol 16(3):335-336

Rosai J (2004) Rosai and Ackerman's surgical pathology, 9th edn. Mosby, Edinburgh, pp 859-867

Roviello F, Cioppa T, Marrelli D, Nastri G, De Stefano A, Hako L, Pinto E (2003) Primary ano-rectal melanoma: considerations on a clinical case and review of the literature. Chir Ital 55:575-580

Sanchis Garcia JM, Pérez Martinez MV, Guijarro Rosaleny J, Palmero da Cruz J (2009) Solution to case 3. Primary malignant melanoma of the rectum. Radiologia 51(1):111-113

Schaik PM, Ernst MF, Meijer HA, Bosscha K (2008) Melanoma of the rectum: a rare entity. World J Gastroenterol 14 (10):1633-1635

Solaz Moreno E, Vallalta Morales M, Silla Burdalo G, Cervera Miguel JI, Diaz Beveridge R, Rayon Martin JM (2005) Primary melanoma of the rectum: an infrequent neoplasia with an atypical presentation. Clin Transl Oncol 7:171-173

Takahashi T, Velasco L, Zarate X, Medina-Franco H, Cortes R, de la Garza L, Gamboa-Dominguez A (2004) Anorectal melanoma: report of three cases with extended follow-up. South Med J 97:311-313

Tanaka S, Ohta T, Fujimoto T, Makino Y, Murakami I (2008) Endoscopic mucosal resection of primary anorectal malignant melanoma: a case report. Acta Med Okayama 62(6):421-424

Wanebo HJ, Woodruff JM, Farr GH, Quan SH (1981) Anorectal melanoma. Cancer 47:1891-1900

Wang G, Eyden B, Yao LF et al (2007) Primary small cell malignant melanoma of the rectum: case report of a very rare tumor. Ultrastruct Pathol 31:315-320

Werdin C, Limas C, Knodell RG (1988) Primary malignant melanoma of the rectum. Evidence for origination from rectal mucosal melanocytes. Cancer 61:1364-1370 